Chimia 46 (1992) 469-476

(c) Neue Schweizerische Chemische Gesellschaft ISSN 0009-4293

\section{The Mixing-Sensitive Product Distribution of Chemical Reactions}

\author{
Paul Rys*
}

\begin{abstract}
The rate of mixing might exert a decisive influence on the product distribution in competitive chemical reactions. This review gives an account of existing mixingsensitive single-phase liquid-liquid chemical reactions where all reactants and products are soluble, and which have the potential to be employed as an exploratory 'microprobe' to investigate the local flow characteristics and the mixing process at the molecular scale. In addition, the appropriate literature references are given to the existing theoretical ad hoc mixing-reaction models and to the recent progress in simulating the coupling between mixing and chemical reaction by numerical calculations.
\end{abstract}

\section{Introduction}

Many chemical reactions are so fast relative to mixing that significant conversion takes place before homogenization down to the molecular scale is reached. In such cases, the bond-breaking and bondforming events mainly occur in regions where concentration gradients are still present. Consequently, the mixing process can have a pronounced effect on the kinetics and the product distribution in competitive reaction systems.

\section{Coupling between Mixing and Chemical Reactions}

A number of models have been proposed which claim to describe and to simulate the influence of mixing processes on the rates of chemical transformations. They have been discussed in several review papers [1-6]. It seems to be widely accepted that the mixing of miscible fluids consists of three stages. It is useful to distinguish them, even though, in practical reaction systems, they may overlap:

- Distribution of one fluid through the other. This process is brought about by ordinary eddy diffusion and causes uni-

*Correspondence: Prof. Dr. P. Rys Swiss Federal Institute of Technology (ETH) CH-8092 Zürich Laboratorium für Technische Chemie formity of the time-average composition in different parts of a cross-section of the fluid stream without decreasing local variations.

- Subdivision of large regions of a given composition into smaller regions by the formation of vortices and by laminar and turbulent stretching. This stage increases the area of contact between regions of different composition, thus facilitating the subsequent mixing stage.

- Molecular diffusion which smoothes out concentration gradients. The reactants interdiffuse, whereby molecules of each type migrate into an environment containing molecules of the other type. This creates a reaction zone in which all the reactants co-exist until the bond-breaking and bond-forming events of the chemical transformations take place. The size of the reaction zone depends on the intrinsic chemical reaction rates. This final mixing stage (micromixing) has proved to be essentivity) of mixing-sensitive chemical reactions.

A more detailed discussion of these mixing processes has already been given in [7]. In spite of extensive theoretical work which has been published on the subject, the mixing processes are far from being clearly understood. Thus, the existing ad hoc mixing-reaction models can only give an order-of-magnitude estimate of the influence which the rate of mixing exerts on the distribution of the chemical reaction products.

A better understanding of the coupling between mixing and chemical reaction is needed for two reasons:

- It would enable one to evaluate the mechanism of chemical reactions even from measured chemical selectivities, which are subject to mixing-disguise.

- It would allow one to control and to optimize the product distribution of mixing-sensitive chemical processes by choosing the appropriate reactor geometry and mixing conditions.

\section{Mixing-Sensitive Chemical Reactions}

For the investigation of mixing effects and their influence on product distribution in competitive chemical reactions, it is inevitable to compare the numerical calculations and the theoretical predictions with experimental data. Such a comparison will then allow to select from the many ad hoc mixing models the one most compatible with physical reality. On the other hand, a well characterized reaction system can also be employed as an exploratory 'microprobe' which would give decisive and new information about the local flow characteristics and the mixing process at the molecular scale. However, the relatively few experimental investigations do not yet permit a thorough and comprehensive evaluation of this kind. Moreover, it is precisely for mixing-sensitive rapid reactions that the intrinsic kinetics essential for the comparison is so often unknown.

This paper gives an account of existing tial for the product distribution (selec-

Scheme 1. Unidirectional Competitive Consecutive Reaction System
$A+B$

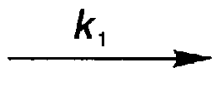
$\mathbf{R}$
primary reaction
$\mathbf{R}+$

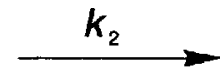


as well as some new mixing-sensitive single phase liquid-liquid chemical reactions where all reactants and products are soluble and which have the potential to be employed as a tool to investigate the mechanism of mixing on the molecular scale. It is not intended, however, to be exhaustive.

Most of the following chemical reaction systems whose product distribution is mixing-sensitive have not been designed to study the coupling between mixing and chemical reaction, but have rather been found accidentally. For the reason of clarity, these reaction systems are often classified according to the kinetic interrelation of their competing chemical events.

\subsection{Competitive Consecutive Reaction System}

Up to now, in all experimentally investigated mixing-sensitive reaction systems belonging to this class, the competing reactions are unidirectional as shown in Scheme I.

Here, four different molecules A, B, R, and $\mathbf{S}$ are involved. The second reaction consumes the primary product $\mathbf{R}$ of the first one, and both are consuming $\mathbf{B}$ concurrently.

Scheme 2. Schematic Representation of the Competitive Consecutive Nitration of Durene by $\mathrm{NO}_{2}{ }^{+} \mathrm{PF}_{6}^{-}$in Nitromethane $\left(20^{\circ}\right)$ [11]

$\mathrm{X}^{-}=\mathrm{PF}_{6}^{-}$

Fig. 1. Influence of the stirring rate on the product distribution in the azo coupling of I-hydroxynaphthalene-6sulfonate with phenyldiazonium ion in $\mathrm{H}_{2} \mathrm{O}$ [23]. $X_{5}$ : relative yield of the bis-azo product $\mathbf{S}$ at $100 \%$ conversion; $u$ : rate of stirring [rev. $\left.\min ^{-1}\right]$.

\subsubsection{Aromatic Nitrations}

Mixing-sensitive product distributions have long been suspected in aromatic nitrations. In many studies the remarkable observation has been reported that the equimolar nitration of durene $(1,2,4,5$ tetramethylbenzene, see Scheme 2) resulted in mainly dinitrodurene and unchanged durene, hardly any mononitrodurene was found [8-11]. Similar observations have been made with other substrates [11-14]. These experimental results are in apparent contradiction to the general knowledge of the mechanism of electrophilic aromatic substitution, according to which the second nitration should be slower than the first by a factor of $>10^{4}$, i.e. $k_{1} / k_{2}>10^{4}$, because of the deactivating effect of the first $\mathrm{NO}_{2}$ group. Some authors attempted to explain the apparently faster second nitration by reaction mechanistic considerations [15] [16]. Many other authors, on the other hand, suggested that mixing effects be the possible cause [9][10][1719]. However, it was not before the early seventies, when these speculations were substantiated by comparing the experimental with the predicted mixing-disguised product distributions [1][2][11-13][20]

[21]. The latter were calculated for a batch reactor [20] and a continuous stirred tank reactor [22] using a simplified mixingreaction model. This comparison is, strictly speaking, possible only because the intrinsic kinetics of the chemical reaction is known: the nitration by nitronium salts is of first order with respect to both the aromatic substrate and the nitronium ion [14].

Unfortunately, the fast nitrations are applicable to the investigation into the coupling of mixing with chemical processes only if the absolute exclusion of moisture can be achieved as, e.g., in small reaction vessels [11-13][20]. In reaction vessels of industrial size where traces of moisture can hardly be completely excluded, the nitronium ion reacts readily with water to yield nitric acid. Therefore, the effective nitronium ion concentration and thus the nitration rate decrease. As a consequence, the mixing process looses its influence on the product distribution.

\subsubsection{Azo Coupling Reactions}

Azo coupling is another reaction that is often disguised by mixing. The coupling reaction of a diazonium ion with an excess of a bifunctional coupling component often yields not only a mixture of the $o$ - and p-monoazo compounds, but also appreciable amounts of the bis-azo product. We have demonstrated earlier on [1][2][21] [23] that the final relative product ratio of the monoazo to the bis-azo compound varies with the stirring rate, and that at high stirring rates the undesired by-product, namely the bis-azo compound, vanishes (Fig. I). Soon after we published our results, various research groups began to evaluate the possibility of using fast azo coupling reactions to test the mixedness in large scale reaction vessels and to evaluate the mixing efficiencies of industrial stirring devices [24][25]. For such test reactions to be widely applicable some of the following requirements are sine qua non: i) the product distribution must be markedly influenced by the rate of mixing;

ii) for practical reasons, the competitive reactions must be chosen so that they can easily be performed in aqueous solutions;

iii) the intrinsic kinetics of the bond-making and bond-breaking chemical events must be known.

With azo coupling reactions the prerequisites $i$ and $i i$ can easily be fulfilled. Referring to the condition $i i i$, in most of the aforementioned studies it was assumed that the competitive reaction system complies with the simplified Scheme 1 and that the primary as well as the secondary azo coupling reaction follows an intrinsic kinetic of second-order, i.e. first order with 
respect to the reactants $\mathbf{A}, \mathbf{B}$, and $\mathbf{R}$. However, as we have pointed out earlier [1][2] [23], such a simplified assumption can only be justified for specific reaction conditions. It seems that this restriction has mostly been ignored in the past, and it is only recently that some of the limitations were restated [26]. Evidently, if one intends to use a competitive azo coupling reaction as a 'microprobe' to evaluate the mechanism of the mixing process and its influence on the product distribution, the exact intrinsic kinetics of all reaction steps involved must first be determined. This must be done over the entire concentration range of all reactants and under all possible reaction conditions prevailing in the mixing zone.

There are various reasons why Scheme $l$ can only approximately describe the competitive consecutive azo coupling reactions of a bifunctional coupling component. This becomes evident, if all possible chemical events are considered (Scheme $3)$ : First, the primary coupling of a bifunctional component generally consists of two parallel reactions, and they in turn may be mixing-sensitive. For example, in the azo coupling of 1-hydroxynaphthalene-6-sulfonate (A) with phenyldiazonium ion (B) the reaction may occur at $\mathrm{C}(2)$ or $\mathrm{C}(4)$. The bis-azo product $\mathrm{S}$ is then formed in the secondary azo coupling reaction from two monoazo products $\mathbf{R - 2}$ and $\mathbf{R}-\mathbf{4}$ that themselves differ in reactivity. Whether both of the isomers R-2 and R-4 are formed, and to what extent this happens depends on the individual chemical structure of the reactants $\mathbf{A}$ and $\mathbf{B}$ as well as the existing local reaction conditions. This must be carefully evaluated for every case studied. Secondly, it must be remembered that an azo coupling reaction liberates protons which even with macroscopic buffering can lead to local $\mathrm{pH}$ gradients in the reaction zone [1][2][23] [27]. In mixing-sensitive reactions, in which these $\mathrm{pH}$ gradients cannot be sufficiently rapidly evened out, this leads to a shift in the preceding acid-base equilibria of the reactants in the mixing zone and, thus, influences the local reaction rates. This is quantitatively represented by the general Rate Expression 1 for the primary $(\mathbf{N}=\mathbf{A} ; \mathrm{j}=1)$ and the secondary $(\mathbf{N}=\mathbf{R}$; $\mathrm{j}=2$ ) azo coupling reaction in the position $n$ of the coupling component $\mathbf{N}$. For the example chosen in Scheme 3, $n$ is 2 or 4 .
Scheme 3. Schematic Representation of a Competitive Consecutive Azo Coupling Reaction [23]

Reactant A: 1-Hydroxynaphthalene-6-sulfonate.

Reactant B: Phenyldiazonium ion.

Product R-2: 1-Hydroxy-2-(phenylazo)naphthalene-6-sulfonate.

Product R-4: 1-Hydroxy-4-(phenylazo)naphthalene-6-sulfonate.

Product S: 2,4-Bis(phenylazo)-1-hydroxynaphthalene-6-sulfonate.

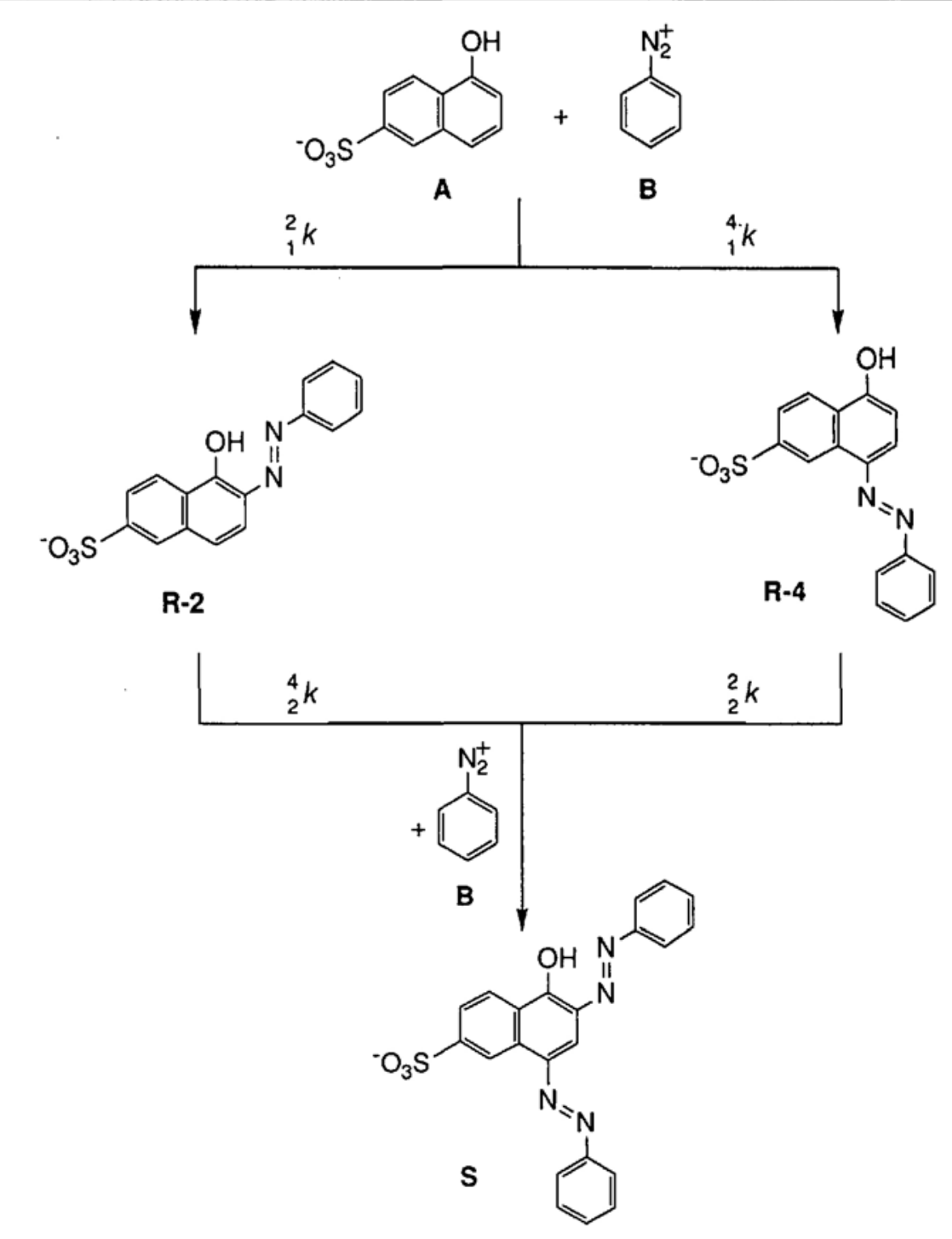

Here,

$r_{\mathrm{j}, n}: \quad$ rate of formation of the azo products $\mathbf{R}-2$ ( $\mathrm{j}=1, n=2, \mathbf{N}=\mathbf{A}), \mathbf{R}-4$ $(\mathrm{j}=1, n=4, \mathbf{N}=\mathbf{A})$ and $\mathbf{S}(\mathrm{j}=2, n$ $=2, \mathbf{N}=\mathbf{R}-\mathbf{4}$, or $n=4, \mathbf{N}=\mathbf{R}-\mathbf{2}$ ), respectively.

${ }_{\mathrm{j}}^{n} k_{\mathrm{I}},{ }_{\mathrm{j}}^{n} k_{-\mathrm{l}},{ }_{\mathrm{j}}^{n} k_{\mathrm{II}, \mathrm{i}}$ intrinsic rate constants of the individual bond-making and bondbreaking steps in the primary $(\mathrm{j}=1)$ and the secondary $(j=2)$ coupling reactions at the position $n$. The value of ${ }_{\mathrm{j}}^{n} k_{\mathrm{II}, \mathrm{i}}$ depends on the reactivity of the present base $\mathrm{i}$

$\frac{K_{\mathrm{N}}}{+10^{-\mathrm{pH}}} \frac{10^{-2 \mathrm{pH}}}{K_{1} K_{2}+10^{-2 \mathrm{pH}}} c_{\mathrm{N}} c_{\mathrm{B}}$
$K_{\mathrm{N}}: \quad$ acidity constant of the reactant $\mathbf{N}$ $(\mathbf{N}=\mathbf{A}, \mathbf{R}-\mathbf{2}$, or $\mathbf{R}-\mathbf{4})$

$K_{1}$ : acidity constant of the diazonium ion

$K_{2}$ : acidity constant of the diazohydroxide

$c_{\text {base, } i}:$ concentration of the base i. In general, the bases involved are water and the components of the buffer

$c_{\mathrm{N}}:$ concentration of the coupling component $\mathbf{N}$

$c_{\mathrm{B}}$ : concentration of the diazo component $\mathbf{B}$

pH: $\quad-\log c_{\mathrm{H}_{+}}$

The concentration terms $c_{\mathrm{N}}$ and $c_{\mathrm{B}}$ encompass all the acidic and basic species of the corresponding reactants $\mathbf{N}$ and $\mathbf{B}$, respectively. Referring for example to the primary azo coupling reaction depicted in 
Scheme $3, c_{N}$ represents the sum of the concentrations of the nonreacting 1-hydroxynaphthalene-6-sulfonate and the corresponding reactive naphtholate. Similarly, $c_{B}$ encompasses the concentrations of the reactive phenyl diazonium ion and its basic nonreactive form, the phenyldiazotate. The acid-base equilibria between these species are locally established at an encounter-controlled rate [28] and, therefore, generally at a much higher rate than all other chemical events which occur. Thirdly, the primary or secondary reaction may exhibit general base catalysis. In this case, the rate of each reaction step is influenced by the local concentration gradient of the various bases $i$ in the mixing layer (l). These and other characteristics of this azo coupling reaction are discussed in full detail in [23]. To summarize, the following requirements must be met in order that mixing-sensitive azo coupling reactions can be approximated by the simplified Scheme 1:

- In the primary reaction only one of the monoazo products is formed preferentially:

- the local buffer capacity in the mixing layer must be high enough so that the released protons can be neutralized;

- for the reaction condition used no general base catalysis should occur, i.e. the condition

$$
{ }_{\mathrm{j}}^{n} k_{-1}<\sum{ }_{\mathrm{j}}^{n_{11, \mathrm{i}}} c_{\text {base }, \mathrm{i}}
$$

must apply in the reaction zone for the primary as well as for the secondary azo coupling reaction.

\subsubsection{Other Mixing-Sensitive Reactions}

The following fast competitive reaction systems have also been used to assess the influence that mixing processes may have on product distribution. However, as not in all cases has the intrinsic reaction kinetics been fully determined, the assessments of mixing effects were, therefore, only qualitative. Mixing dependent product distributions have been observed with the iodination of 1-tyrosine [29][30] and

Scheme 4. Unidirectional Competitive Parallel Reaction System

\begin{tabular}{|c|c|c|}
\hline$A+B$ & $k_{3}$ & $\mathbf{P}$ \\
\hline & $k_{4}$ & \\
\hline
\end{tabular}

Scheme 5. Competitive Bromination of 4-Bromo-1,3-dimethoxybenzene and 2-Bromo-1,3,5trimethoxybenzene in $\mathrm{MeOH}$ [35][43][45]

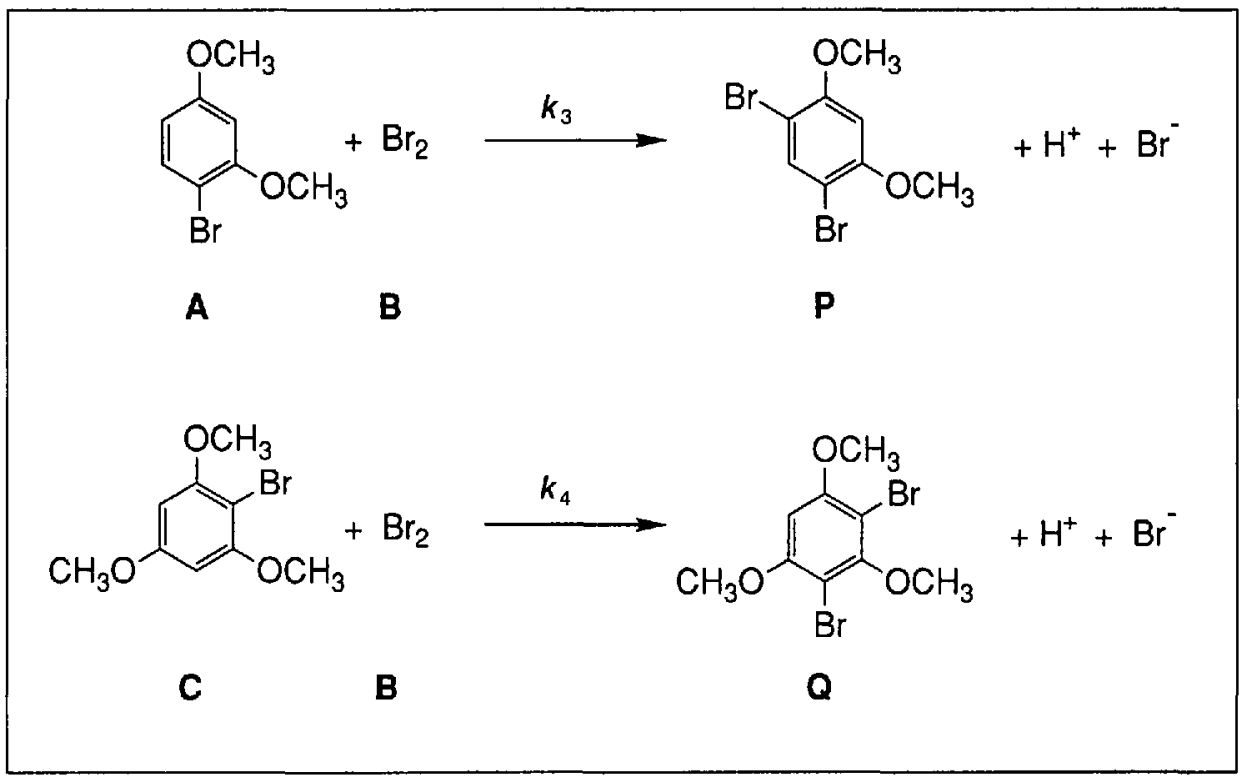

Scheme 6. Competitive Bromination of 2-Bromo-1,3,5-trimethoxybenzene and its Deuterated Isomer in $\mathrm{MeOH}$ [35]

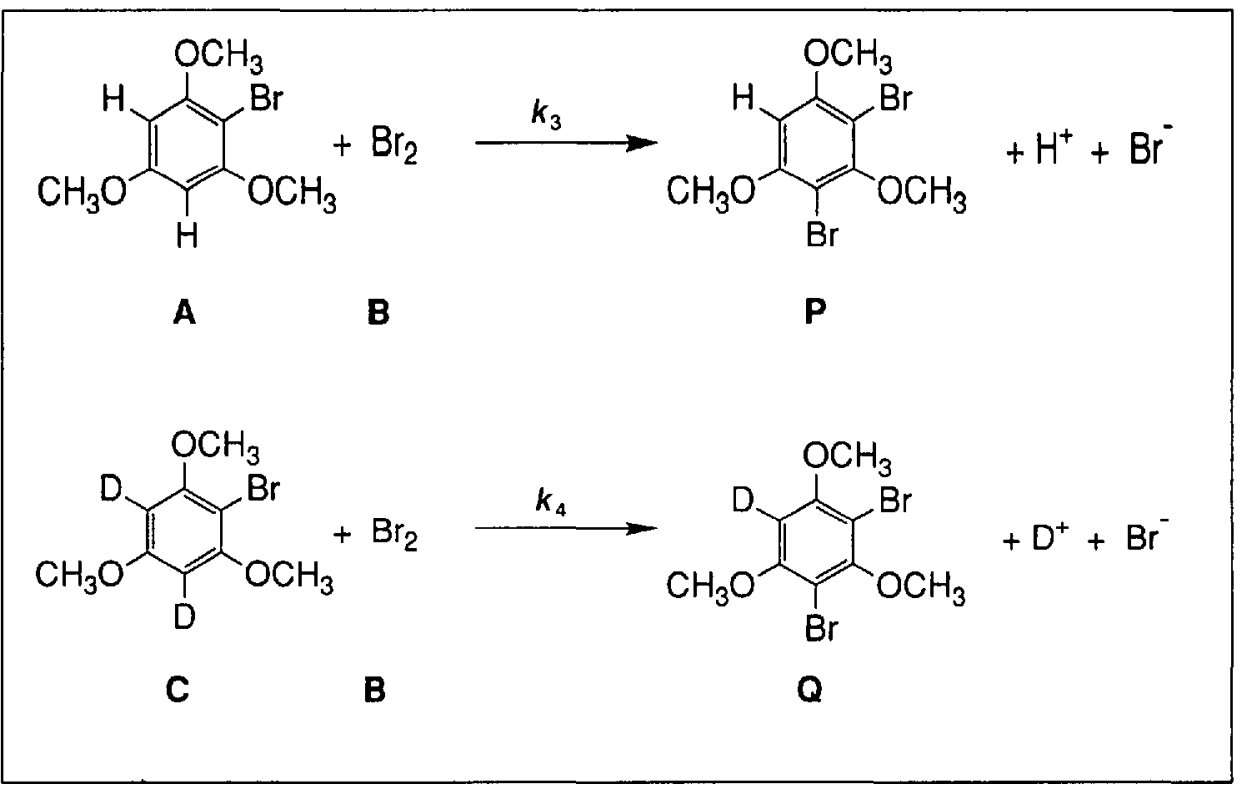

Scheme 7. Competitive Azo Coupling of 6-Amino-4-hydroxy-2-naphthalenesulfonate in $\mathrm{H}_{2} \mathrm{O}$ [36]<smiles>[X]c1cccc(N=Nc2c(S(=O)(=O)[O-])cc3ccc(N)cc3c2[N+](=O)[O-])c1</smiles> 
p-cresol [31], with the alkaline catalyzed hydrolysis of glycol diacetate [31][32], and with competitive radical-chain reactions [47]. Further kinetic studies need to be carried out before these reactions can be adopted as test systems. Some fast polymerizations [33] have also shown the sensitivity to mixing, but in general the reaction mechanisms are very complex, and they are by no means fully understood.

\subsection{Competitive Parallel Reaction System}

Here, the substrates $\mathbf{A}$ and $\mathbf{C}$ compete in two parallel reactions for the same reactant $\mathbf{B}$. In case that both reactions are unidirectional (Scheme 4), and that each of them is first order with respect to the reactant $\mathbf{B}$ and the respective substrate $\mathbf{A}$ or $\mathbf{C}$, the intrinsic differential selectivity is given by the expression

$$
\frac{\mathrm{d} c_{\mathrm{P}}}{\mathrm{d} c_{\mathrm{Q}}}=\frac{k_{3}}{k_{4}} \frac{c_{\mathrm{A}}}{c_{\mathrm{C}}}
$$

However, if the competitive reaction system is mixing-sensitive, i.e. at least one of the appropriate Damköhler numbers (= mixing moduli) is much greater than unity, the selectivity factor $k_{3} / k_{4}$ loses its importance in determining the observed product distribution. As model calculations show [1][2][20][35][38][45][46], such a situation occurs when the sensitivity to mixing increases.

\subsubsection{Aromatic Brominations}

The dependence of product distribution on stirring rate was recognized as early as 1926, with the competitive bromination of a mixture of aromatic substrates [34]. Among the many possible mixingsensitive competitive parallel reaction systems, only two are known today to have their intrinsic kinetics carefully examined [35][43]. Both reaction systems are concurrent aromatic brominations using molecular $\mathrm{Br}_{2}$ with $\mathrm{MeOH}$ as the solvent. In one case, a mixture of 4-bromo-1,3-dimethoxybenzene and 2-bromo-1,3,5-trimethoxybenzene was brominated leading to the corresponding dibromo products (Scheme 5). In the other case, the competitive bromination of 2-bromo-1,3,5-trimethoxybenzene and its isomer deuterated at C(4) and C(6) was studied (Scheme 6).

The intrinsic kinetics including all the bond-making and bond-breaking chemical reaction steps of an aromatic bromination with molecular $\mathrm{Br}_{2}$ has proved to be very complex [35]. Here, only the most important features for the understanding of the mixing effect on the final product distribution are summarized:

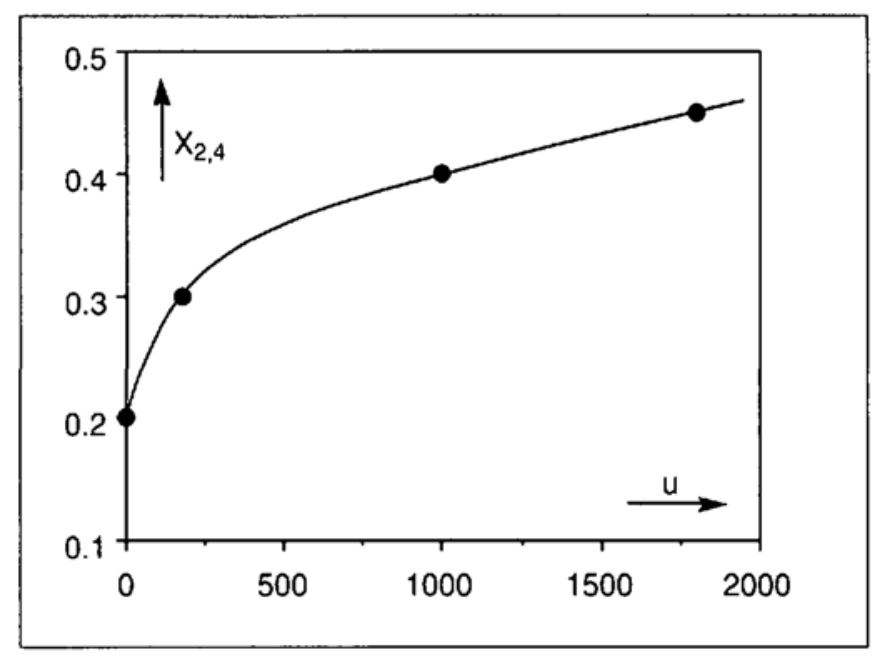

Fig. 2. Influence of the stirring rate on the isomer distribution in the competitive bromination of resorcinol with molecular $\mathrm{Br}_{2}$ in $\mathrm{MeOH}\left(22^{\circ}\right)$ [41]. $X_{2,4}$ : relative yield of the 2,4-dibromo isomer at $100 \%$ conversion; $u$ : rate of stirring [rev. $\min ^{-1}$ ]

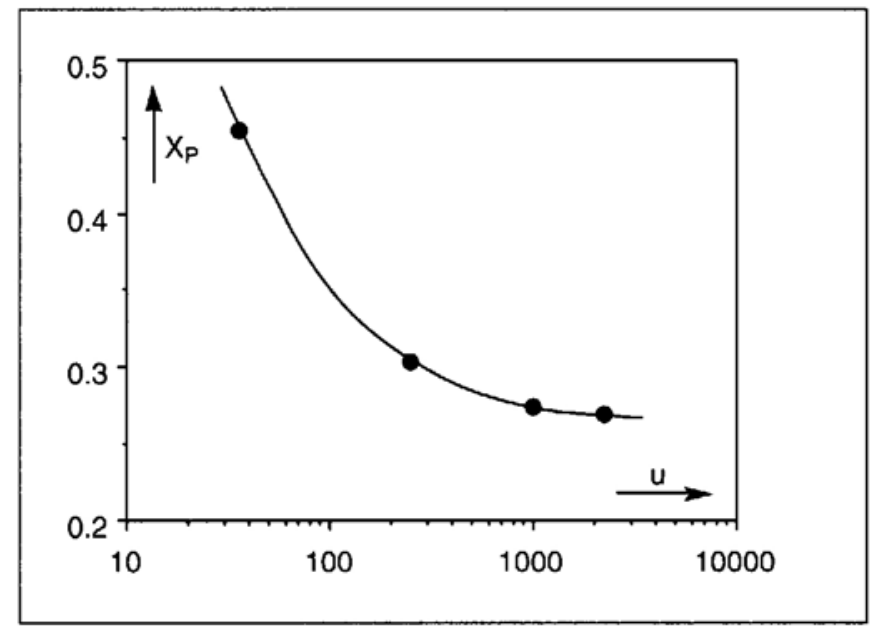

Fig. 3. Influence of the stirring rate on the isomer distribution in the competitive bromination of I-(tert-butyl)-3methoxybenzene in $70 \%$ $\mathrm{MeOH}\left(20^{\circ}\right)[43] . X_{\mathrm{p}}$ : relative yield of the 4-bromo isomer at $100 \%$ conversion; $u$ : rate of stirring [rev. $\mathrm{min}^{-1}$ ]

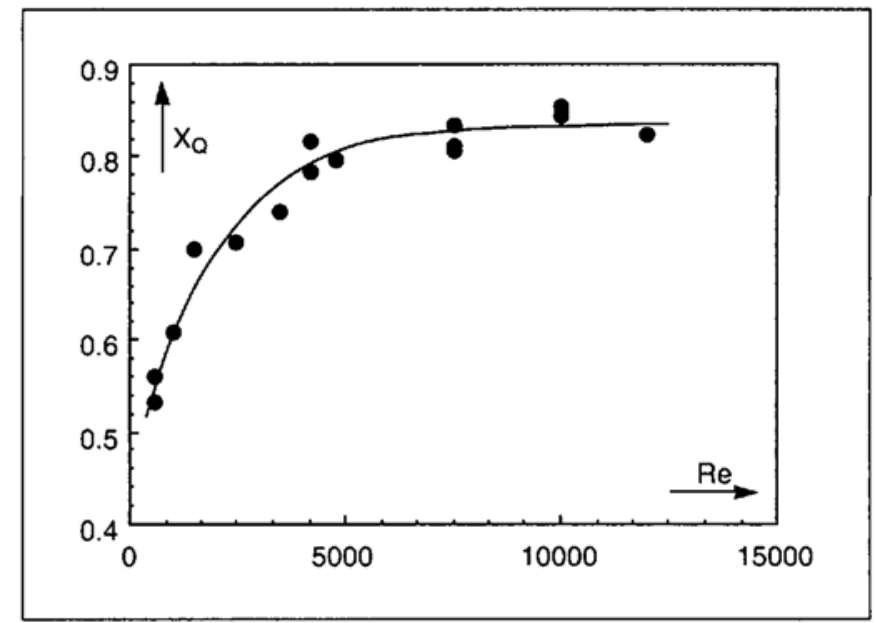

Fig. 4. Influence of the stirring rate on the isomer distribution in the azo coupling of 1-hydroxynaphthalene-3-sulfonate with 2-nitrophenyldiazonium ion in $\mathrm{H}_{2} \mathrm{O}\left(25^{\circ}\right)$ [44]. $X_{\mathrm{Q}}$ : relative yield of the 2 isomer at $100 \%$ conversion; Re: Reynolds number.

i) The brominations depicted in Schemes 5 and 6 follow the intrinsic kinetic expression (3)

Here,

$r_{\mathrm{N}}$ : rate of bromination of substrate $\mathbf{N}$ ${ }_{N} k_{\mathrm{I}},{ }_{N} k_{-\mathrm{I}},{ }_{N} k_{11, \mathrm{i}}:$ intrinsic rate constants of

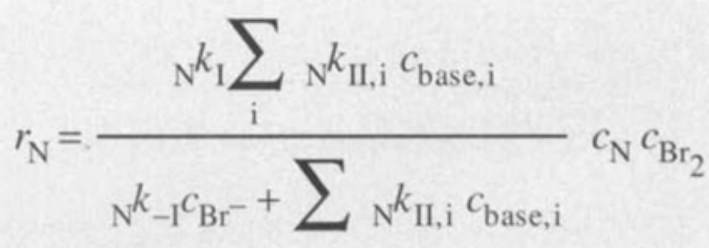


the individual bond-making and bond-breaking steps in the bromination of substrate $\mathbf{N}$.

The value of ${ }_{N} k_{\text {II, }}$ depends on the reactivity of the base $i$

$c_{\mathrm{Br}^{-}}-$concentration of bromide ion

$c_{N}$ : concentration of substrate $\mathbf{N}$

$c_{\mathrm{Br}_{2}}$ : concentration of $\mathrm{Br}_{2}$

ii) These brominations liberate protons and $\mathrm{Br}^{-}$anions, resulting in $\mathrm{pH}-$ and bromide concentration gradients within the reaction zone. As shown in Eqn. 3 the evolved $\mathrm{Br}^{-}$ions can slow down the overall chemical event. According to our previous investigation [35], this happens for the bromination of the substrates $\mathbf{A}$ or $\mathbf{C}$ depicted in Scheme 5 at bromide concentrations higher than $10^{-1}$ or $10^{-3} \mathrm{~mol} / 1$, respectively. Under these conditions, a general base catalysis starts to show up.

Scheme 8. Spectrum of Products (without $\mathrm{H}^{+}$and $\mathrm{Br}^{-}$) in the Competitive Bromination of Resorcinol in $\mathrm{MeOH}$ [41]

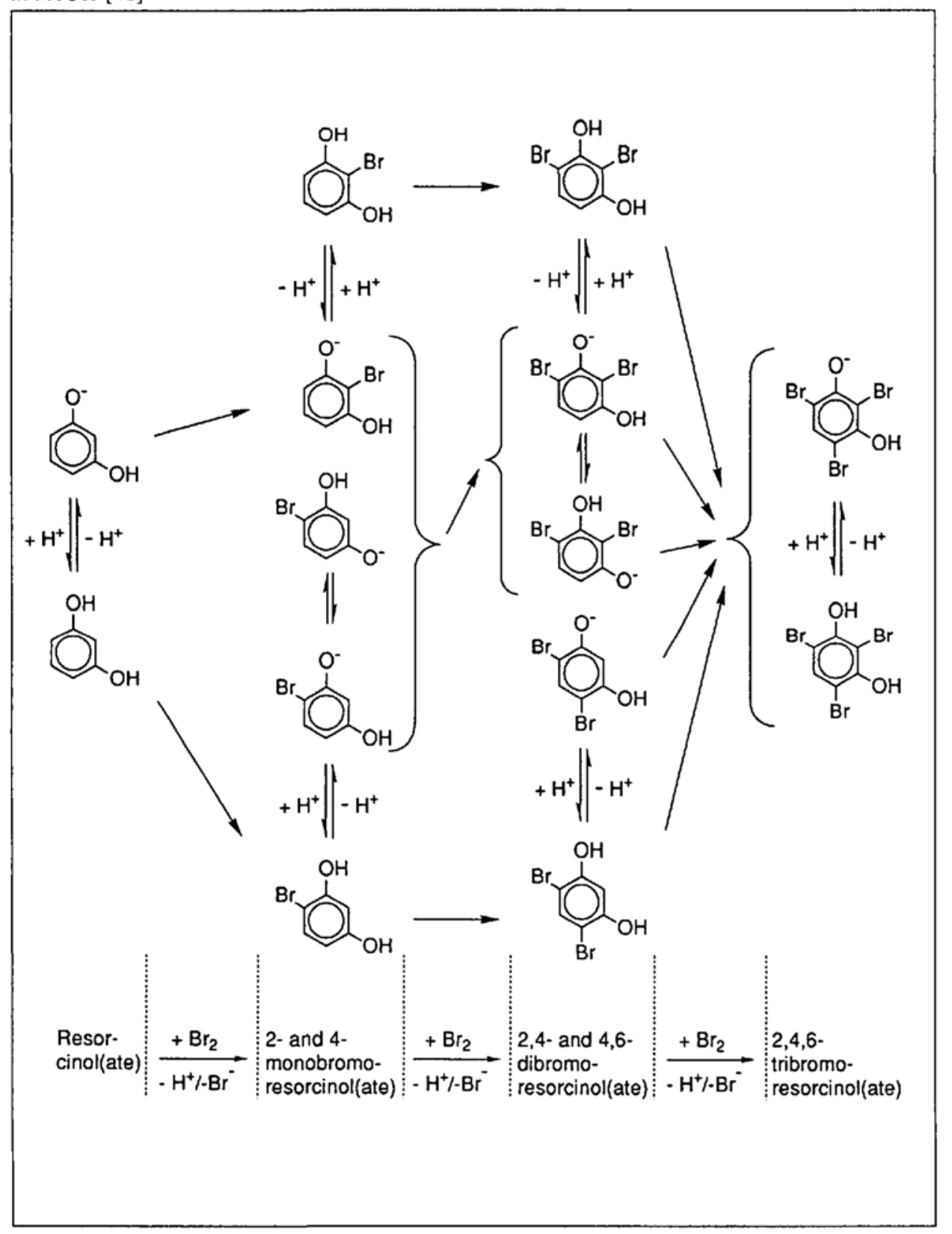

Consequently, the bromination rate then becomes dependent on the various bases $\mathrm{i}$ present in the reaction zone.

iii) The rate-reducing action of the $\mathrm{Br}^{-}$ ion generated, is not only brought about by the kinetic term ${ }_{\mathrm{N}} k_{-\mathrm{I}} c_{\mathrm{Br}}-$ in Eqn. 3, but also by the fact that the $\mathrm{Br}^{-}$ion combines with $\mathrm{Br}_{2}$ to form the $\mathrm{Br}_{3}^{-}$ion in a very fast equilibrium (4). This lowers the concentration of bromine, $c_{\mathrm{Br}_{2}}$, and thus according to Eqn. 3 also the bromination rate.

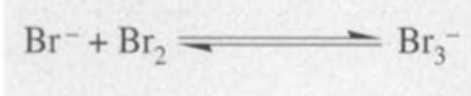

\subsubsection{Azo Coupling Reactions}

In the azo coupling of aminonaphthols the position at which the reaction takes place depends on the $\mathrm{pH}$ applied (Scheme 7). At low pH values, the coupling occurs preferentially at the aromatic ring which 


\subsubsection{Isomer Distribution Determined by} Mixing-Sensitive Substrate Selectivity

Scheme 7 shows an example of a competitive reaction system in which two isomers are formed from two different substrates identified as two distinct acid-base equilibrium forms of the same compound. A similar situation has been identified in the competitive bromination of resorcinol [1][2][41][42]. Here, however, the reaction system is extremely complex, as it consists of a superposition of consecutive and parallel chemical events occurring simultaneously: if resorcinol in $\mathrm{MeOH}$ is treated with an equimolar amount of molecular $\mathrm{Br}_{2}$, monobromo isomers are obtained in addition to dibromo isomers and 2,4,6-tribromoresorcinol [41][42]. The degree of substitution decreases when the rate of stirring is increased, i.e. with more effective mixing. An analysis of the ratio of the dibromo isomers in the products obtained under conditions which give mainly dibromo substitution reveals that the relative proportion of the 2,4 -isomer also increases with increasing stirring rate (Fig. 2). In principle, there are two possible reasons which may explain the results. On the one hand, this finding may be a consequence of a positional selectivity (see 3.3.2), provided that the bromination at various reaction sites of resorcinol exhibits different kinetic order. So far, nobody has been able to evaluate this intrinsic bromination kinetics exactly. On the other hand, however, it has been shown [41] that the formation of 2,4-dibromo isomer proceeds via the resorcinolate or monobromoresorcinolate, whereas the 4,6dibromo isomer is formed from resorcinol derivatives. This means that the ratio of the structural isomers is a function of substrate selectivity, as shown in Scheme 8.

The substrate ratio resorcinol/resorcinolate, and hence the ratio of the dibromo isomers depends on the $\mathrm{pH}$ of the reaction solution. Since protons are liberated during the bromination (Schemes 5, 6, and 8), the $\mathrm{pH}$ in the reaction zone decreases with time. As a consequence, in the reaction zone the 4,6-dibromo isomer is formed preferentially as the reaction continues. With intensive stirring, the $\mathrm{pH}$ gradient is more rapidly destroyed, and the isomer ratio is shifted in favor of 2,4-dibromoresorcinol.

\subsubsection{Isomer Distribution Determined by} Mixing-Sensitive Positional Selectivity

It is important to draw attention to the fact that a product distribution, which is solely a consequence of positional (regio-) selectivity, can be altered by mixing effects only if the competing reactions have a difference in kinetic order with

Scheme 9. Competitive Bromination of 1-(tert-Butyl)-3-methoxybenzene in 70\% MeOH [43]

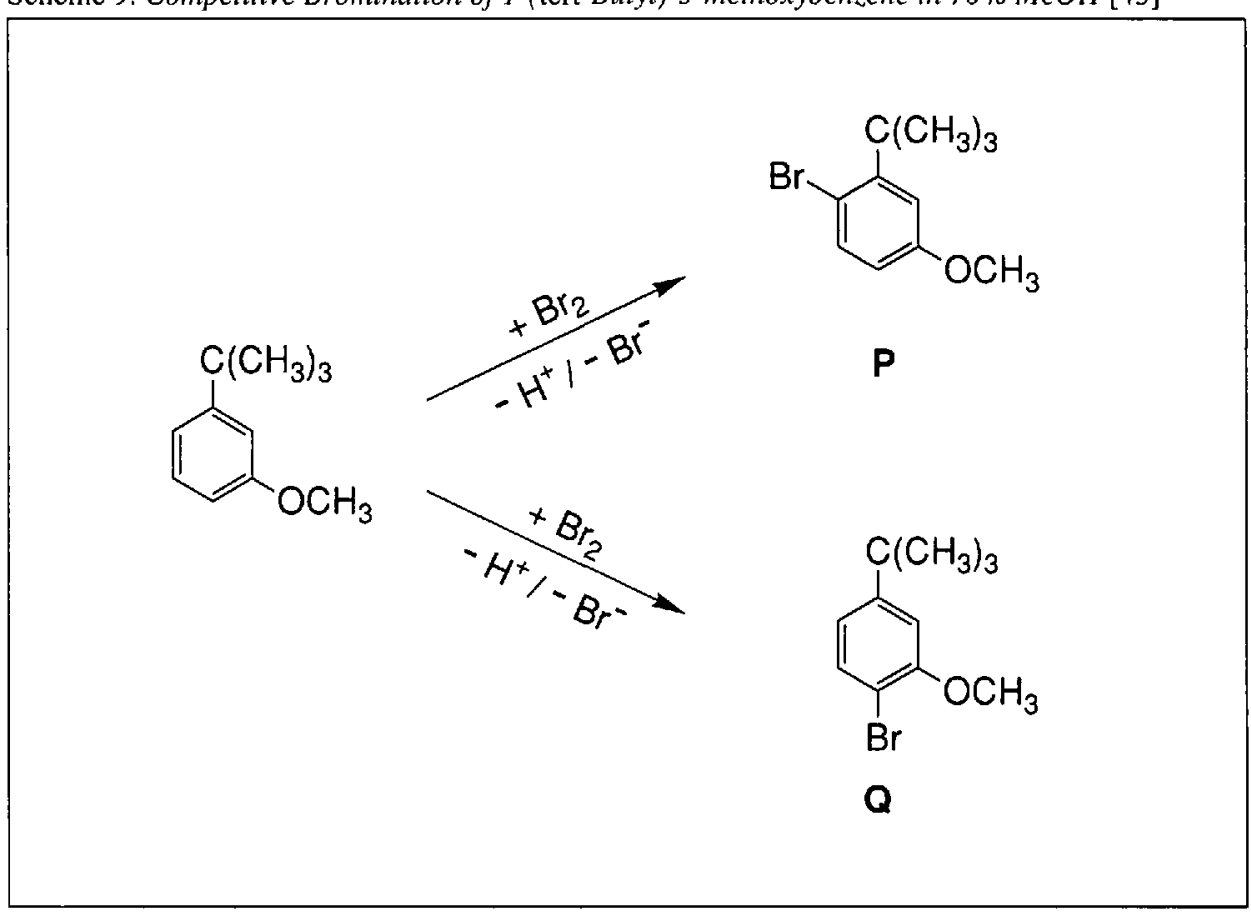

Scheme 10. Competitive Azo Coupling of 1-Hydroxynaphthalene-3-sulfonate with 2-Nitrophenyldiazonium Ion in $\mathrm{H}_{2} \mathrm{O}$ [44]

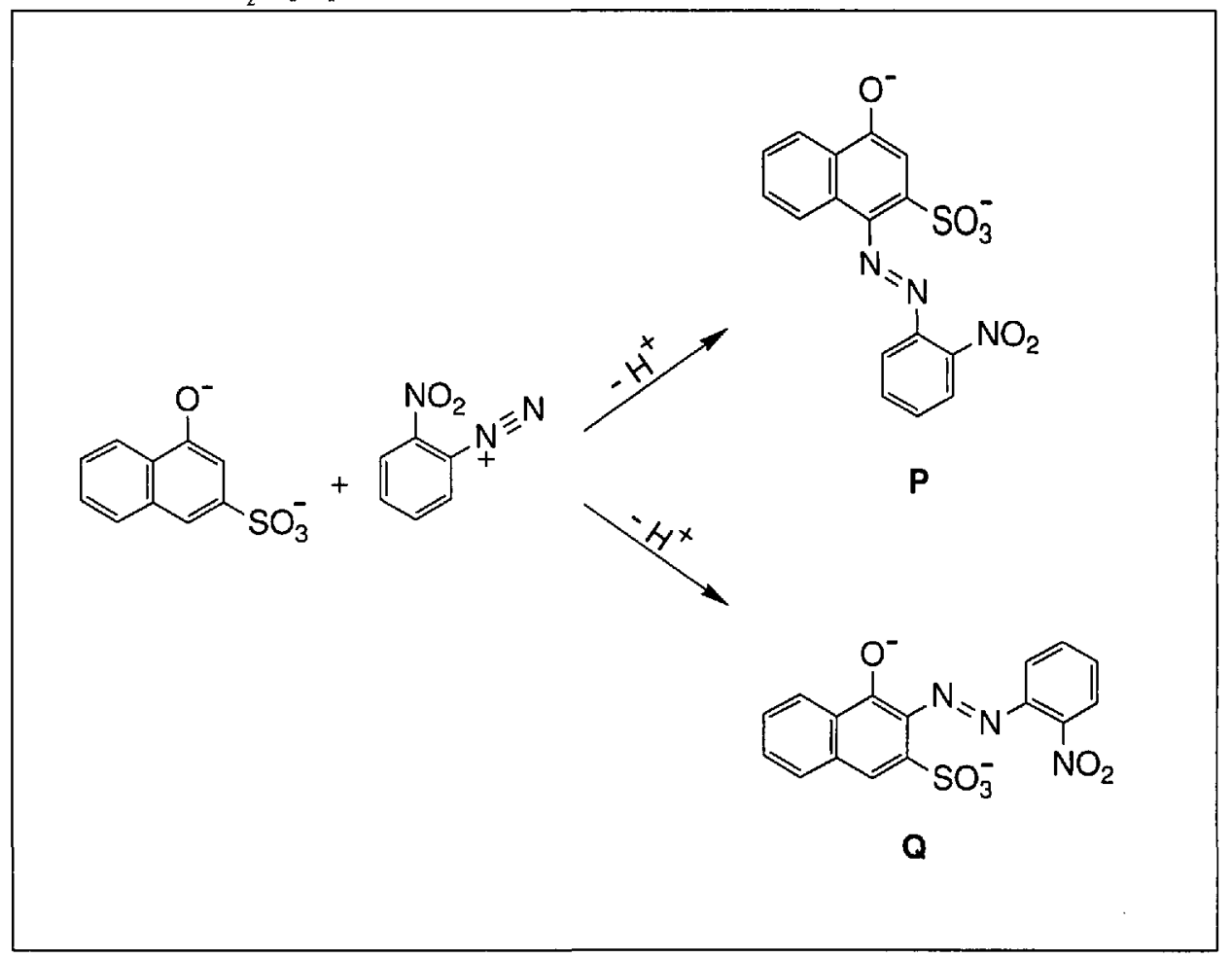

respect to at least one of the reagents. These aspects are of great importance in our recent [43][44] and continuing efforts to design a competitive mixing-sensitive reaction system suitable for the evaluation of mixing process mechanism. In electrophilic aromatic substitutions, the most mixing-sensitive positional selectivities can be obtained, if one of the competing reactions is sterically hindered and hence exhibits a general base catalysis. This has been clearly demonstrated by the bromination of 1-(tert-butyl)-3-methoxybenzene with molecular $\mathrm{Br}_{2}$ (Scheme 9 and Fig. 3)
[43] and for the azo coupling of 1-hydroxynaphthalene-3-sulfonate with 2-nitrophenyldiazonium ion (Scheme 10 and Fig. 4) [44]. In these detailed studies, it has been carefully elucidated that both reactions, bromination at the position ortho to the $t$ Bu group, and the para azo coupling, are catalyzed by the bases $i$ present in the respective reaction zones. An increase in stirring rate decreases the concentration of the added bases within the reaction zone and, as a consequence, the rate of formation of the corresponding products $\mathbf{P}$. 
The author is deeply indepted to many enthusiastic and expert members of his research group, such as Drs. F. Pfister, P. Eugster, F. Nabholz, E. Crivelli, M. Aellen, H. Belevi, E. Dedeoglu, M.B. Simson, A.C. Skaria, J.P.G. Rohner, and M.B. Wehrli. Some results of their studies have provided the experimental basis for this paper. Their work was financially supported in part by the Swiss National Science Foundation and the Kommission zur Förderung wissenschaftlicher Forschung, KWF ([7][23][27][35][41][45]) and partly by the $S$ wiss Chemical Industries, Basel ( $\mathrm{Ciba-}$ Geigy $A G$, Sandoz $A G$, and F. Hoffmann-La Roche $A G$ : [7][11][12][41][43-46]).

Received: September 30, 1992

[1] P. Rys, Angew. Chem. Int. Ed. 1977, 16, 807.

[2] P. Rys, Pure Appl. Chem. 1981, 53, 209.

[3] J. Baldyga, J. R. Bourne, in 'Encyclopedia of Fluid Mechanics' Ed. N. P. Cheremisinoff, Gulf Publ.Comp., Houston, 1986, Vol. I, pp. 147

[4] J. Baldyga, J. R. Bourne, Chem. Eng. Commun. 1984, 28, 231.

[5] J. R. Bourne, Proc. 8th Int. Symp. Chem. React. Eng. Symp. Ser. No. 87, 1984, Inst. Chem. Eng., pp. 543.

[6] R. David, J. Villermaux, Chem. Eng. Commun. 1987, 54, 333.

[7] M.B. Wehrli, F.S. Rys, P. Rys, Proc. Int Workshop on Chem. React. in Turbulent Liquids, Lausanne, 15.-16. 4. 91, Cambridge Univ. Press, Cambridge, in press.

[8] R. Fittig, P. Jannasch, Z. Chem. 1870, 162; J.W. Nef, Justus Liebigs Ann. Chem. 1886, 237, 1; J.C. Cain, Ber. Disch. Chem. Ges. 1895, 28, 967; L. Rügheimer, M. Handel, ibid. 1896, 29, 2171; F. Francis, J. Chem. Soc. 1906, 89, 1; Ber. Dtsch. Chem. Ges. 1906, 39, 3798 .

[9] G.Illuminati, M.P.Illuminati, J.Am. Chem. Soc. 1953, 75, 2159; R.C. Fuson: 'Reactions of Organic Compounds', Wiley, New York, 1962, pp. 33.

[10] S.B. Hanna, E. Hunziker, T. Saito, H Zollinger, Helv. Chim. Acta 1969,52, 1537.

[11] F. Pfister, Dissertation ETH, No. 5052 , Zürich 1973; F. Pfister,P.Rys, H.Zollinger, Helv. Chim. Acta 1975, 58, 2093.

[12] F. Nabholz, Dissertation ETH, No. 5949 , Zürich 1977; F. Nabholz, P. Rys, Helv. Chim. Acta 1977, 60, 2937.

[13] A.K. Manglik, R.B. Moodie, K. Schofield, E. Dedeoglu, A. Dutly, P. Rys, J. Chem. Soc., Perkin Trans. 2 1981, 1358.

[14] Review in K. Schofield: 'Aromatic Nitration', Cambridge University Press, Cambridge, 1980.

[15] R. Willstätter, H. Kubli, Ber. Dtsch. Chem. Ges. 1909, 42, 4151.

[16] G.A. Olah, Acc. Chem. Res. 197I, 4, 240.

[17] P.F. Christy, J.H. Ridd, N.D. Stears, J. Chem. Soc. B 1970, 797.

[18] J.H. Ridd in 'Studies on Chemical Structure and Reactivity', Methuen, London, 1960.

[19] J.H. Ridd, Acc. Chem. Res. 1971, 4, 248.

[20] F. Nabholz, R.J. Ott, P. Rys, Helv. Chim.
Acta 1977, 60, 2926; Proc. 2nd Eur. Conf. on Mixing, Cranfield 1978; P. Rys, Acc. Chem. Res. 1976, 9, 345.

[21] P. Rys, Gordon Res. Conf. 'Organic Reactions and Processes', New Hampton, 1973.

[22] H. Belevi, J.R. Bourne, P. Rys, Helv. Chim. Acta 1981, 64, 1630; Chem. Eng. Sci. 1981, 36, 1649.

[23] E. Crivelli, Dissertation, ETH No. 5811, Zürich, 1976; J.R. Bourne, E. Crivelli, P. Rys, Helv. Chim. Acta 1977, 60, 2944.

[24] J.R. Bourne, U. Mörgeli, P. Rys, Proc. 2nd Eur. Conf. on Mixing, Cranfield, 1978; J.R. Bourne, F. Kozicki, P. Rys, Chem. Eng. Sci. 1981, 36, 1643; J. R. Bourne, F. Kozicki, U. Mörgeli, P. Rys, ibid. 1981, 36, 1655.

[25] W. Angst, J.R. Bourne, F. Kozicki, Proc. 3rd Eur. Conf. on Mixing, Cranfield, 1979; J.R. Bourne, Chem. Eng. Commun. 1982, 16, 79; Chem. Eng. Sci. 1983, 38, 5; J.R. Bourne, S. Rohani, Proc. 4th Eur. Conf. on Mixing Cranfield, 1982; Chem. Eng. Sci. 1983, 38, 911; W. Angst, J.R. Bourne, R.N. Sharma, ibid. 1982,37, 1259; V.G. Jensen, ibid. 1983, 38, 1151; O. Bolzern, J.R. Bourne, ibid. 1983, 38, 999; I. Chem. E. Symp. Ser. 87 1984, 543; W. Angst, J.R. Bourne, P. Dell'Ava, Chem. Eng. Sci. 1984, 39, 335; J.R. Bourne, G. Tovstiga, Chem. Eng. Commun. 1985, 36, 67; Chem. Eng. Res. Des. 1988, 66, 26; J.R. Bourne, C. Hilber, G. Tovstiga, Chem. Eng. Commun. 1985, 37, 293; J. Baldyga, J.R. Bourne, Chem. Eng. Sci. 1988, 43, 107; J.R. Bourne, K. Ravindranath, S. Thoma, J. Org. Chem. 1988, 53, 5166; J.R. Bourne, C.P. Hilber, Trans. I. Chem. E. 1990, 68, 51; J. GarciaRosas, S. Petrozzi, Chimia 1990, 44, 366.

[26] J.R. Bourne, O.M. Kut, J. Lenzner, H. Maire, Ind. Eng. Chem. Res. 1990, 29, 1761.

[27] H. Belevi, Dissertation, ETH No. 6579 , Zürich, 1980; H. Belevi, J.R. Bourne, P. Rys, Helv. Chim. Acta 1981, 64, 1599, 1618.

[28] M. Eigen, Angew. Chem. 1963, 75, 489.

[29] E.L. Paul, R.E. Treybal, AlChE. J. 1971, $17,718$.

[30] J.R. Bourne, S. Rohani, Chem. Eng. Res. Des. 1983, 6I, 297.

[31] A. Zoulalian, J. Villermaux, Adv. in Chem. 1974, 133, 348.

[32] K.T. Truong, J.C. Methot, Can. J. Chem. Eng. 1976, 54, 572.

[33] J. Villermaux, L. Blavier, Chem. Eng. Sci. 1984, 39, 87; J. Villermaux, M. Pons, L. Blavier, EFCE, Publ. Ser., Chem. React. Eng. Edinburgh 1984, 37, 533.

[34] A.W. Francis, J. Am. Chem. Soc. 1926, 48, 655.

[35] E. Dedeoglu, Dissertation, ETH No. 755!, Zürich, 1984.

[36] R. Kaminski, U. Lauk, P. Skrabal, H. Zollinger, Helv. Chim. Acta 1983, 66, 2002.

[37] C. Wittwer, H. Zollinger, Helv. Chim. Acto 1952, 35, 1209; ibid. 1954, 37, 1954; H. Zollinger, 'Color Chemistry', 2nd edn., Verlag Chemie, Weinheim, 1991.

[38] J. Baldyga, J.R. Bourne, Chem. Eng. Sci. $1990,45,907$

[39] W.S. Tolgyesi, Can. J. Chem. 1965, 43, 343.

[40] J.P. Candlin, J. Halpern, D.L. Trimm, $J$. Am. Chem. Soc. 1964, 86, 1019; P.B. Wood,
W.C.E. Higginson, J. Chem. Soc. (A) 1966, 1645.

[41] P. Eugster, Dissertation, ETH No. 5013, Zürich, 1973.

[42] J.R. Bourne, P. Rys, K. Suter, Chem. Eng. Sci. 1977, 32, 711 .

[43] M.B.Simson, Dissertation, ETH No. 8258, Zürich, 1987

[44] A.C. Skaria, Dissertation, ETH No. 8531 Zürich, 1988.

[45] M. A. Aellen, Dissertation, ETH No. 5998, Zürich, 1977.

[46] J.G.P. Rohner, Dissertation, ETH No.9363, Zürich, 1991.

[47] R.R. Bard, J.F. Bunnett, X. Creary, M.J. Tremelling, ibid. 1980, 102, 2852; M.J. Tremeling, J.F. Bunnett, J. Am. Chem. Soc. 1980, 102, 7375; G.F. Meijs, J.F. Bunnett, A.L.J. Beckwith, ibid. 1986, 108, 4899. 